SHORT REPORT

\title{
Large outbreak of measles in London: reversal of health inequalities
}

\author{
P Atkinson, C Cullinan, J Jones, G Fraser, H Maguire
}

Arch Dis Child 2005;90:424-425. doi: 10.1136/adc.2003.048892

$\mathrm{R}$ eported rates of MMR vaccine uptake in London at 2 years of age fell from the mid-1990s to $73 \%$ in late 2001 compared to $84 \%$ for England as a whole. ${ }^{1}$ Nationally, coverage decreased by a greater proportion in affluent compared to deprived areas. ${ }^{2}$ Mathematical modelling has predicted this drop would be sufficient to sustain measles transmission in nine health authorities in England and Wales, seven of them in London. ${ }^{3}$ However, substantial measles outbreaks remained rare in London from 1996 to mid-2001, occurring primarily as small clusters in religious and other communities opposed to vaccination. The largest outbreak consisted of 43 confirmed cases in east London in early $2001{ }^{4}$

In late December 2001 a cluster of confirmed measles cases was reported among preschool children in south London, the start of the largest outbreak since the mid-1990s. This paper describes the outbreak, and examines the characteristics of the children affected, with particular reference to immunisation history and socioeconomic status.

\section{PARTICIPANTS, METHODS, AND RESULTS}

From January 2002, in response to the outbreak, Consultants in Communicable Disease Control in London were asked to actively report all notified cases on a weekly basis. These data were aligned with saliva test results from the Public Health Laboratory Service (PHLS) Enteric, Respiratory and Neurological Virus Laboratory.

From December 2001 to May 2002, 129 confirmed cases by positive saliva test and 451 suspected cases were reported, the peak of the outbreak occurring in late February. Forty per cent of all cases were aged under 12 months, $75 \%$ were 5 years or under. For all cases where vaccination history was available (70\%), 98\% had no record of receiving any measles vaccine. Vaccination history was poorly recorded among the older children aged 2 years or more (who should have received one dose by this age). Over half $(56 \%)$ of this age group, where history was available, had no record of receiving any measles vaccine (although the numbers were small).

The geographical distribution of confirmed cases, based on residential postcodes where available $(84 \%)$, showed the majority of children lived in south inner London (fig 1). The majority of cases were located in more affluent wards, based on the Department of the Environment, Transport and Regions (DETR) Index of Deprivation. This pattern was compared to the distribution of 89 confirmed cases of meningococcal disease with onset during the same time period. In the absence of data describing socioeconomic status, individual cases were assigned a deprivation score based on their ward of residence. The mean DETR score for measles cases was significantly lower than that of meningitis cases (two tailed $t$ test, $\mathrm{p}=0.02$ ).

\section{DISCUSSION}

We report here that the largest outbreak of confirmed measles cases in London since the completion of the national introduction of MMR vaccine in 1994 occurred in a largely unvaccinated group of children living in relatively affluent parts of the capital. The distribution of measles cases is in contrast to many studies that associate poor vaccine uptake and high infectious disease rates with social deprivation. ${ }^{5}{ }^{6}$

We assigned ward-level deprivation scores to individual cases, assuming the characteristics of the local area describe the socioeconomic status of the children. In doing so, we committed the ecological fallacy, but in the absence of additional data this seems a reasonable approach, and feedback from public health staff investigating the cases suggests the association with affluence is real.

It may be argued that had the source of the outbreak occurred elsewhere, for example in less prosperous parts of the capital, measles may have spread into more deprived wards, affecting these observations. While possible, we argue transmission in the present outbreak was largely dependent on low usage of MMR vaccine in more affluent areas.

The London outbreak of 2001 shows an interesting reversal of health inequality, with more measles cases seen in areas of affluence, in contrast to many other childhood conditions.

\section{ACKNOWLEDGEMENTS}

We acknowledge the work of Consultants in Communicable Disease Control, in contributing to the surveillance of both measles and meningitis across London.

\section{Authors' affiliations}

P Atkinson, C Cullinan, Southwark PCT, London, UK

J Jones, G Fraser, H Maguire, Health Protection Agency, London, UK

Competing interests: none declared

Correspondence to: Dr P Atkinson, Southwark PCT, 258 Waterloo Rd, London SE1 8RG, UK; phil.atkinson@southwarkpct.nhs.uk

Accepted 5 August 2004

\section{REFERENCES}

1 Public Health Laboratory Service. Immunisation. COVER programme: October to December 2001. Commun Dis Rep CDR Wkly 2002;12(13) (available from www.phls.co.uk).

2 Middleton E, Baker D. Comparison of social distribution of immunisation with measles, mumps, rubella vaccine, England, 1991-2001. BMJ 2003;326:854

3 Gay N, Crook P, Rush M, et al. Evaluating the potential for sustained measles transmission in England. London: Public Health Laboratory Service Communicable Disease Surveillance Centre, 2001.

4 Ramsay ME, Jin L, White J, et al. The elimination of indigenous measles transmission in England and Wales. J Infect Dis 2003;187(suppl 1).

5 Sharland $M$, Atkinson $P$, Maguire $H$, et al. Lone parent families are an independent risk factor for lower rates of childhood immunisation in London. Commun Dis Rep 1997;7(11):169-72.

6 Stuart JM, Middleton N, Gunnell DJ. Socioeconomic inequality and meningococcal disease. Commun Dis Public Health 2002;(4):327-8. 


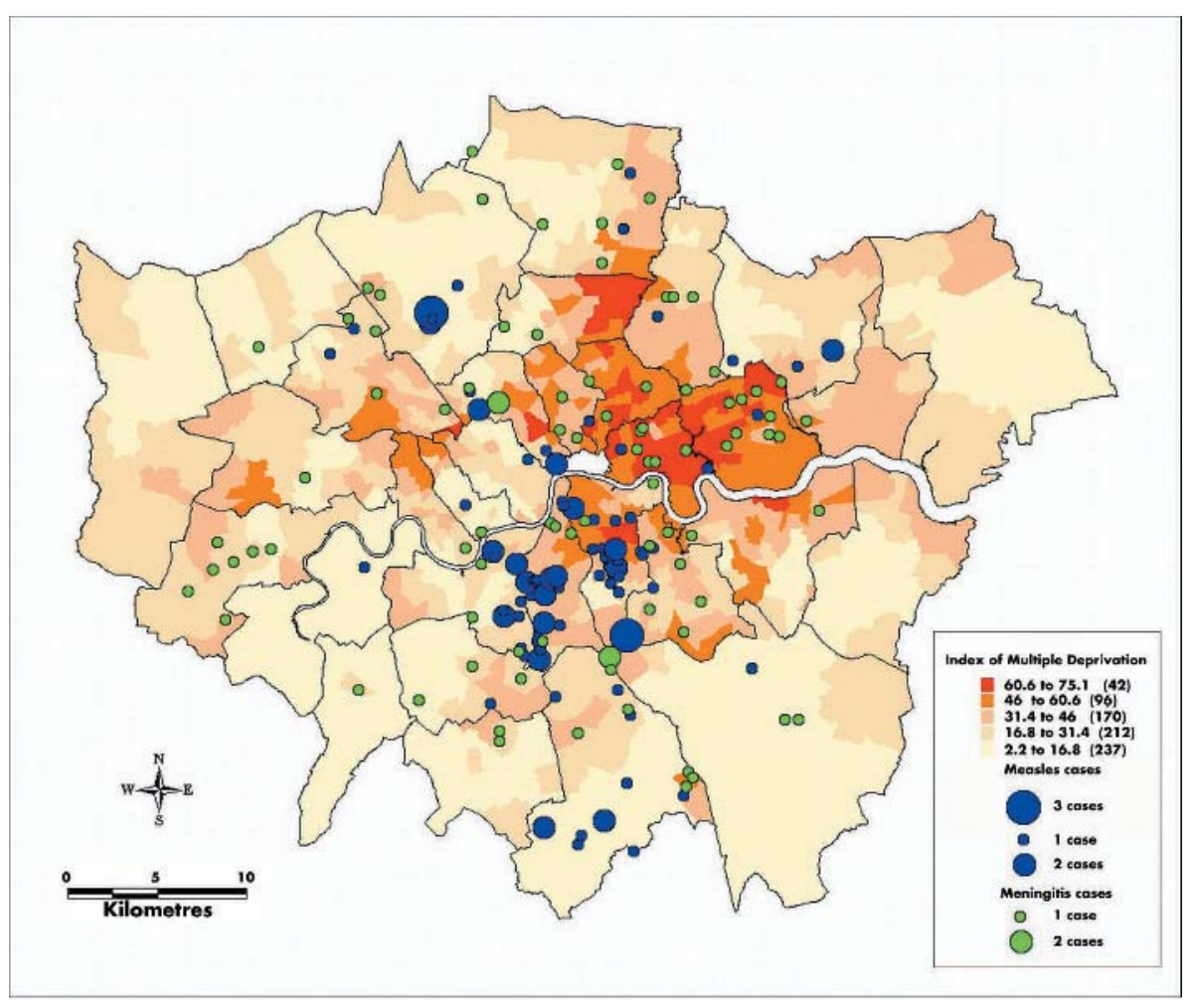

Figure 1 Geographical distribution of confirmed cases.

\section{IMAGES IN PAEDIATRICS}

\section{Congenital cutaneous candidiasis with funisitis}

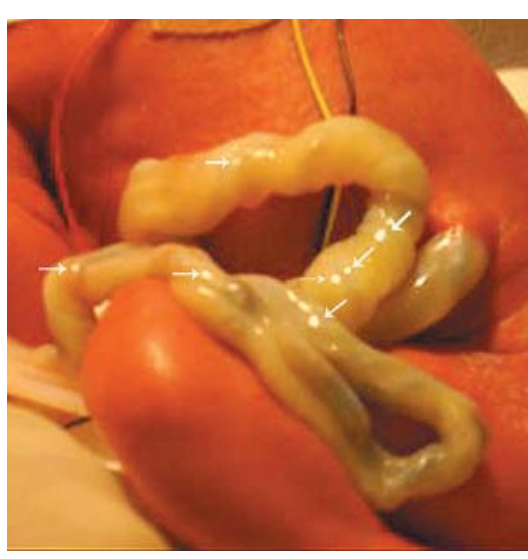

Figure 1 Focal pearly lesions noted in cord (some arrowed).

\begin{abstract}
ongenital candidiasis is associated with increased perinatal mortality and adverse neurological outcomes, with extensive periventricular leucomalacia being common. ${ }^{1}$ This baby was the first of twins born by emergency caesarean section at 29 weeks gestation after cervical suture removal. Initial examination revealed multiple pearly white spots embedded in the umbilical cord (fig 1) and an extensive maculopapular erythematous skin eruption with some fissuring. This rapidly evolved into a dry whitish scaly rash. Congenital cutaneous candidiasis with candida funisitis was suspected and amphotericin commenced. Surface swabs and gastric aspirate grew Candida albicans and histology of the umbilical cord revealed necrotising funisitis. There was a marked polymorphonuclear leucocytosis. C reactive protein remained normal. Her subsequent respiratory course was complicated by episodic lobar collapse with excessive thick mucoid secretions. A history of repeated vaginal thrush during pregnancy was obtained.

Congenital candidiasis in extremely preterm infants has been associated with: presence of an IUCD during pregnancy, characteristic chorioamnionitis and funisitis, a leucocytosis, and infective alveolitis. ${ }^{1}$ Funisitis macroscopically has small circumscribed pale yellow-white nodules with microscopic subamnionic focal lesions embedded in fibrinoid exudates surrounded by inflammatory cells. ${ }^{2}$ Rapid histology may help confirm the diagnosis. ${ }^{3}$ A marked leucocytosis with increased non-segmented granulocytes and normal C reactive protein has been described. ${ }^{1}$ Early invasive cutaneous candidiasis has also been noted in extremely premature infants: prompt recognition and treatment with amphotericin has been reported to improve outcome. ${ }^{4}$
\end{abstract}

A K Sinha, M F Hird

Neonatal Unit, Royal London Hospital, Whitechapel, London E1 1BB, UK; a.k.sinha@qmul.ac.uk

\section{REFERENCES}

1 Baud O, Boithias C, Lacaze-Masmonteil T, et al. Maternofetal disseminated candidiasis and high-grade prematurity. Arch Pediatr 1997;4:331-4.

2 Qureshi F, Jacques SM, Bendon RW, et al. Candida funisitis: a clinicopathologic study of 32 cases. Pediatr Dev Pathol 1998;1:118-24.

3 Schwartz DA, Reef S. Candida albicans placentitis and funisitis: early diagnosis of congenital candidemia by histopathologic examination of umbilical cord vessels. Pediatr Infect Dis J 1990;9:661-5.

4 Melville C, Kempley ST. Treatment of invasive candida infection in neonates with congenital cutaneous candidiasis. Pediatrics 2001;108:216. 